\title{
The Regional Characteristics and Development of Plant Landscape Construction in Sichuan Garden
}

\author{
Shilan Tang ${ }^{1, *}$, Jinghui Liang ${ }^{1}$ \\ ${ }^{1}$ College of Tourism\&Landscape Architecture, Guilin University of Technology, Guilin 541006, China
}

\begin{abstract}
Sichuan garden is one of the important regional schools in Chinese classical gardens. The construction of plant landscape in Sichuan gardens show obvious regional characteristics. By sorting out the types of the Sichuan gardens, this paper selects the representative classical gardens and modern gardens in Sichuan area as research cases to study plant landscape construction. From the perspective of landscape architecture and urban natural ecological environment, this paper summarizes the regional characteristics of Sichuan gardens in the construction of plant landscape, and explores the role of Sichuan regional plant landscape construction in displaying the local regional culture, improving the quality of life of urban residents, the urban living environment and urban ecological environment. Taking Du Fu Thatched Cottage, Qingyang Palace, Wenshu Temple and Living-water Garden in Chengdu as examples, this paper analyses the regional construction methods of plant landscape in Sichuan gardens, summarizes the regional characteristics of plant landscape construction in Sichuan gardens, in order to provide reference for the improvement of urban ecological environment.
\end{abstract}

\section{Introduction}

With the acceleration of urbanization in China, people are increasingly aware of the importance of inventory planning and sustainable development in urban and rural environment. Landscaping is an important part of urban and rural planning and one of the elements that constitute the vitality and cultural identity of a city. Sichuan garden is one of the important regional schools in Chinese classical gardens. Classical gardens in Sichuan have the beauty of classicism, nature and ecology. Classical gardens in Sichuan are also characterized by elegance, philosophy and literature. On the basis of classical Sichuan gardens, modern Sichuan gardens pay more attention to the improvement and protection of ecological environment with plants. Whether it is classical Sichuan gardens or modern Sichuan gardens, they both improve the quality of the environment through plant construction and have a beneficial impact on the life of local residents. The plant construction in Sichuan gardens shows obvious regional characteristics, which is one of the vitality sources of cities in Sichuan. This paper takes the classical and modern Sichuan gardens as the research cases, and focuses on the regional characteristics of plant construction in Sichuan gardens, so as to protect plants and inherit the regional culture in Sichuan area, and provide reference and consideration for modern plant landscape design, plant protection, improvement of urban ecological environmental quality and improvement of residents' quality of life.

\section{The historical process of Sichuan gardens}

Sichuan gardens are distributed in the Sichuan basin centered on the Chengdu Plain, mainly including the present-day Chengdu, Mianyang, Deyang, Ya 'an, Meishan, Leshan and other places in Sichuan Province. The pre-Qin period belongs to the embryonic period of Sichuan gardens. The main representative garden is Nanshan Garden. During the Qin, Han, Wei, Jin and Southern and Northern Dynasties, Sichuan gardens were in the early stage of development. During the Han Dynasty, there are records of temple gardens being built on Mount Emei. During the Wei, Jin and Southern and Northern Dynasties, temple gardens at Mount Qingcheng and Mount Emei had already been of great scale. During this period, in addition to the temple gardens on Mount Qingcheng and Mount Emei, the Erwang Temple in Dujiangyan are also quite representative. Sui, Tang and Song dynasties are the prosperous period of Sichuan gardens. Many gardens in Sichuan were built in this period. The main representatives are $\mathrm{Du} F u$ Thatched Cottage, Wangjiang Park, East Lake, etc. During the Yuan, Ming and Qing dynasties, Sichuan gardens developed slowly. It is mainly for the tang and Song dynasties garden maintenance, development and reconstruction. In the Republic of China, urban parks began to be built in Sichuan. The first type was newly built urban parks, such as Shaocheng Park, which commemorates the Revolution of 1911. The second type

\footnotetext{
* Corresponding author: 455631359@qq.com
} 
of urban parks takes the original classical gardens in Sichuan as urban parks and rebuilt and expanded them. Nowadays, on the original basis, Sichuan gardens pay more attention to the improvement of the environment and the improvement of the lives of local residents. The representative example is the Living-water Garden.

\section{The characteristics of plant landscape construction in Sichuan gardens}

The first is that many plant constructions in Sichuan gardens come from allusions and are closely related to the culture of local intellectuals. Second, the plant landscape construction of Sichuan gardens pursues philosophy, hoping to inspire the resonance of those who enjoy the scenery in the gardens. The third is that the plants selected for planting in the gardens are generally plain in color and can be integrated with the surrounding environment, embodies the beauty of nature and ecology. The fourth is that the plant construction of Sichuan gardens pursues ecological and environmental protection, which can constitute a good ecological environment. Finally, on the basis of building a harmonious ecological environment with plants, plant landscape construction can be closely integrated with the lifestyle of local residents.

The following will be combined with the actual cases to elaborate.

\section{Typical cases of plant landscape construction in Sichuan gardens}

\subsection{The plant landscape construction of classical gardens in Sichuan}

Classical gardens in Sichuan can be divided into ancestral gardens, temple gardens, government office gardens, private gardens, mausoleum gardens [1], and mainly ancestral gardens, temple gardens.

\subsubsection{Ancestral garden: Du Fu Thatched Cottage}

$\mathrm{Du} \mathrm{Fu}$ Thatched Cottage is one of the typical classical gardens in Sichuan. Du Fu Thatched Cottage was built in 761 A.D. The main tourist attractions related to plants include: Plum Garden, Bamboo Garden, Huanhua Brook, Mini-Scape Garden, Thatched Cottage, etc. At present, $\mathrm{Du} \mathrm{Fu}$ Thatched Cottage was reconstructed and expanded into $\mathrm{Du} \mathrm{Fu}$ Thatched Cottage Museum. The garden is mainly divided into three functional areas: heritage area (Thatched Cottage), garden area (Plum Garden), service area.

(1) Armeniaca mume: the use of allusions

In $\mathrm{Du} \mathrm{Fu}$ Thatched Cottage, Armeniaca mume is cultivated as an important flowering plant. The Armeniaca mume is mainly planted in the Poetry Hall and the Plum Garden of the heritage area. The heritage area is mainly arranged in a regular pattern, with a series of commemorative buildings arranged in a symmetrical manner along the central axis.
Poetry Hall is a memorial building on the central axis with abundant plant community. Around Poetry Hall, Armeniaca mume is planted. One of the main reasons for planting Armeniaca mume is that there are many poems about Armeniaca mume in Du Fu's poems, and the other is that there are records of planting Armeniaca mume in the renovation and expansion of Du Fu Thatched Cottage in previous dynasties. For example, a poem from the Northern Song Dynasty, records: "Spring Outing Huanhua Brook, where do Salix babylonica and Armeniaca mume want to go". Another example is Lu You's poem: "When I was traveling west of Jincheng, I was drunk as mud for Armeniaca mume. From Qingyang Palace to Huanhua Brook, the fragrance of Armeniaca mume has been 20 li. From these records, it can be seen that in the Northern Song Dynasty, there were Armeniaca mume planted on the road from Qingyang Palace to $\mathrm{Du} \mathrm{Fu}$ Thatched cottage ${ }^{[2]}$. The garden area of the Du Fu Thatched Cottage also has a specially opened Plum Garden. Gardenia jasminoides is used for the shrub layer on both sides of the road, and Ophiopogon japonicus is used for the lower ground around the road. The main building is surrounded by two bonsai trees in the form of Podocarpus macrophyllus to highlight the classical charm and highlight the main building. The Plum Garden is planned in a natural pattern, without too much memorial significance of the landscape constructed on the main axis. Mainly through the garden bridges, waterside pavilions and many flowering plants constitute a series of landscape. In the Plum Garden, flowering plants with warm colors such as Armeniaca mume and Malus spectabilis are used as the main landscape, and on this basis, other cold-toned woody plants and herb are added. Such as: Magnolia denudata, Osmanthus fragrans, Gardenia jasminoides, etc. The landscape color composed by them is relatively plain and pure, which is the garden area with obvious seasonal changes of plants in the Du Fu Thatched Cottage.

(2) Bamboo and thatch: the beauty of nature and ecology

The natural and ecological features of Du Fu's Thatched cottage are embodied in the old site of Thatched Cottage. The Thatched Cottage is a continuation of the central axis of the heritage area. It is not on the central axis of the memorial ancestral hall in the garden, and the garden adopts a natural layout. The former residence of Thatched Cottage was built simply with thatch as its roof, which has a deep meaning of commemoration. There is more nature and ecology outside the buildings than on the central axis. The former residence of Thatched Cottage is surrounded by bamboo forests, which are planted around the water, layered and layered, with abundant layers of plants. The water in front of the hut is matched with bamboo, hedge and curved wall as a close shot. This collocation makes the spatial sense of the whole space has been further expanded. In addition to bamboo, Cinnamomum camphora, Platycladus orientalis, Salix babylonica and Phoebe zhennan are planted around the Thatched Cottage, and Acer palmatum is used as the finishing touch of the landscape. 


\subsubsection{Temple garden: Qingyang Temple}

As a city landscapes in Sichuan, Qingyang Palace is a Taoist garden in Chengdu. The earliest construction can be traced back to the Zhou Dynasty. In the Tang Dynasty, QingYang Palace used to be the royal residence. During the Ming Dynasty, due to the war, most of the buildings were destroyed, but now it is mainly rebuilt in the Qing Dynasty ${ }^{[3]}$.

(1) The landscapes of main axis: the use of allusions, the pursuit of philosophy

Qingyang Palace, lying north to south, forms a series of buildings according to the terrain. The buildings on the main axis include temple gate, Lingzu Hall, Mingyuan Hall, Bagua Pavilion, Sanqing Hall, Doumu Hall, Sanguan Hall, etc.

With the number of buildings on the central axis, plants are gradually enriched, and the canopy line rises gradually. The Metasequoia glyptostroboides has been planted in the outermost part of Qingyang Palace, which makes the space beautiful in rhythm. The Bagua Pavilion is one of the representative buildings. In order to show the quiet atmosphere of Qingyang Palace, a large number of plain-colored plants are planted around the Bagua Pavilion. In front of the Bagua Pavilion, Cinnamomum camphora and Podocarpus macrophyllus are arranged. Behind the Bagua Pavilion, two peach blossoms are planted. This method of planting is 'planting trees in front of the temple, planting flowers behind the courtyard ${ }^{[4]}$, The Common Camellia is planted on both sides of the Bagua Pavilion. One of the reasons is the communication and integration of Confucianism, Taoism and Buddhism in Sichuan, and the other reason is that the Common Camellia has the meaning of center and circle in Sanskrit ${ }^{[5]}$.

(2) Tea Garden: closely related to the lifestyle of the local people

At the end of the central axis of Qingyang Palace is the Tea Garden, which is the recreational space of Qingyang Palace. According to the lifestyle of local residents, many tea houses are set up in the Tea Garden, which has become an important place for the recreation of the surrounding residents. In order to construct good recreational space, the Tea Garden planted many tall trees and placed many stone benches, stone tables and pavilions under the trees. Stone tables, stone tables and many trees constitute a larger recreational space and the central axis of the solemn space form a contrast. Behind the Tea Garden belongs to the Taoists` living area. The planning mode of the living area all adopts the natural pattern layout. The living area is not only planted with Cinnamomum camphora, Ginkgo biloba, Metasequoia glyptostroboides, but also planted with Phoebe zhennan, Sophora japonica and Taxus baccata, etc. The small trees have a brighter hue than those planted on the central axis of Qingyang Palace. The plants planted in the living area include Hibiscus mutabilis, Amygdalus persica, Prunus armeniaca, Osmanthus fragrans, Malus spectabilis, Prunus Cerasifera, etc. The shrubs planted in the living area include Ancuba japonica, Melaleuca bracteata, Gardenia jasminoides, etc. Ophiopogon japonicus is widely used as ground cover plants in living area. The plants planted in Taoist gardens are generally use plain colors. Most of the plants planted in Taoist gardens belong to broad-leaved evergreen plants. The deciduous broad-leaved plants planted in the garden are mainly used to embellish color and enhance seasonal sense of plant communities.

\subsubsection{Temple garden: Wenshu Temple}

Wenshu Temple, built in the Sui Dynasty, is one of the temple gardens in Chengdu. The characteristics of the plant construct in Wenshu Temple are the use of allusions and the pursuit of philosophy. The main building of The Wenshu Temple is symmetrical along the central axis and belongs to the architectural style of western Sichuan. The garden part of the Wenshu Temple is planned in a natural pattern. The trees planted in the garden include Ficus virens, Cinnamomum japonicum, Podocarpus macrophyllus, Cinnamomum camphora, Phoebe zhennan, Ginkgo biloba, Metasequoia glyptostroboides, Salix babylonica, Cedrus deodara, and Michelia alba, etc ${ }^{[4]}$. In the temple gardens of Sichuan province, the Michelia alba is often replaced by the Ficus virens. Michelia alba is one of the "five trees and six flowers" in the temples, and Cinnamomum camphora is an important raw material for making Buddhist beads in Buddhist temples [6]. The Wenshu Pavilion in the Wenshu Temple is surrounded by trees and shrubs in the shape of pagodas. The outer wall of The Wenshu Temple is constructed by combining the red wall with bamboo forests or Metasequoia glyptostroboides.

\subsection{The plant landscape construction of modern gardens in Sichuan}

The plant landscape construction of modern gardens in Sichuan pays more attention to the ecological environment and is committed to forming a good ecological environment.

The typical example is the Living-water Gardenin Chengdu. Living-water Park is an urban constructed wetland park, is located in Chengdu`s Funan River bank. One of the main reasons for building the park is to improve the water quality of Funan River. The water in the park is filtered by aquatic flora to improve the water quality of Funan River.

The core of the plant construction consists of 6 plant ponds and 12 plant beds. Plant ponds and plant beds purify the water level by level. They mimic the landscape of the Huanglong Scenic and Historic Interest Area in Sichuan Province ${ }^{[7]}$.

The main plants arrangement in the plant bed and plant pond are Sagittaria trifolia, Phragmites communis, Acorus calamus, Acorus gramineus, Typha angustata, Cyperus alterniflolius, Curculigo capitulate, Aspidistra elatior, Pistia stratiotes, etc. Some plants not only purification of water quality, water conservation, improve the environment, but also have ornamental value. People can view and admire the forms of plants, such as Curculigo capitulate, Acorus gramineus and 
Aspidistra elatior or the flowers and leaves of plants, such as Pistia stratiotes and Eichhornia crassipes, etc ${ }^{[8]}$. At the same time, there are a variety of fish, insects and amphibians symbiotic with plants in the plant ponds and plant beds. Living-water Garden constructed a good artificial wetland plant pond and plant bed ecosystem and wildlife habitat.The planting of land plants in the Living-water Garden simulated the natural vegetation communities in western Sichuan. In addition to indigenous plants such as Hibiscus mutabilis, Ginkgo Biloba, Ficus Virens, etc., the plant landscape in the Living-water Garden also introduces unique and national wild and rare plant species from Emei area of Sichuan Province, such as Michelia Wilsonii, Rhododendron, Alsophila Spinulosa,etc. The plant landscape construction of the Living-water Garden has not only regional characteristics, but also the beauty of wild and nature ${ }^{[9]}$.

Living-water Garden builds a harmonious ecological environment through the plant landscape construction. On this basis, it has become a famous popular science education base and an important place for local residents' recreation because of its ecological environment featuring science popularization, appreciation and recreation. And garden through plant landscape construction can be closely integrated with the lives of local residents.

Table 1. The regional characteristics of plant landscape construction in Sichuan gardens

\begin{tabular}{|c|c|c|c|}
\hline Type & Classification & $\begin{array}{l}\text { Typical } \\
\text { case }\end{array}$ & Characteristic \\
\hline \multirow{3}{*}{$\begin{array}{l}\text { Classical } \\
\text { garden }\end{array}$} & $\begin{array}{l}\text { Ancestral } \\
\text { garden }\end{array}$ & $\begin{array}{c}\text { Du Fu } \\
\text { Thatched } \\
\text { Cottage }\end{array}$ & \multirow{3}{*}{$\begin{array}{l}1 \text { The use of } \\
\text { allusions } \\
2 \text { The pursuit of } \\
\text { philosophy } \\
3 \text { The beauty of } \\
\text { nature and } \\
\text { ecology }\end{array}$} \\
\hline & \multirow{2}{*}{$\begin{array}{l}\text { Temple } \\
\text { garden }\end{array}$} & $\begin{array}{c}\text { Qingyang } \\
\text { Temple }\end{array}$ & \\
\hline & & $\begin{array}{l}\text { Wenshu } \\
\text { Temple }\end{array}$ & \\
\hline $\begin{array}{l}\text { Modern } \\
\text { garden }\end{array}$ & & $\begin{array}{l}\text { Living- } \\
\text { water } \\
\text { Garden }\end{array}$ & $\begin{array}{c}\text { Improvement of } \\
\text { the ecological } \\
\text { environment }\end{array}$ \\
\hline
\end{tabular}

\section{Conclusion}

Sichuan garden is one of the regional schools of Chinese classical gardens. Plant landscape construction in Sichuan gardens not only reflects the spiritual culture of the people in Sichuan Province, but also plays an important role in improving the urban environment. Classical gardens in Sichuan are good at using allusions in the construction of plants, and they combine the construction of plant landscape with the culture of local intellectuals, so as to arouse the philosophical thinking of the viewers. The plants selected in the gardens are plain in color and can be integrated with the surrounding environment. The environment created by construction of plant landscape has the beauty of nature and wild. On the basis of classical gardens in Sichuan, modern gardens in Sichuan pay more attention to the improvement and protection of ecological environment through plant landscape construction. Both classical and modern Sichuan gardens construct an ecologically harmonious environment through plant landscape construction, and on this basis try to integrate closely with the lives of local residents, so as to improve the urban ecological environment and improve the quality of life of local residents.

At present, the researches on plant landscape construction of Sichuan gardens has not been complete and systematic, and the newly built landscape gardens in Sichuan often lose their regional characteristics and do not play an obvious role in the improvement of ecological environment. In order to provide reference for plant landscape construction of Sichuan gardens, to protect the regional characteristics of Sichuan gardens and to improve the ecological environment and urban living environment, more detailed and systematic researches are needed.

\section{References}

1. Q.B Chen, Y.P Yang. Xishu Garden [M]. Beijing: China Forestry Press. 2010.

2. B. Jiang, X.D He. Culture of Mei flower in the Chinese traditional garden of the Chengdu $\mathrm{Du} \mathrm{Fu}$ Thatched Cottage [J]. Journal of Beijing Forestry University, 2015, 37 (S1): 94-96.

3. L.X. Wang. Analysis on Taoist Culture Implications of Architectures of Qingyang Taoist Temple in Chengdu [J]. Journal of Mianyang Teachers 'College, 2018, 37(03):139-143+149.

4. H.Z. Liu. Study on Plant Landscape Construction and inheritance of Classical gardens in Sichuan [D]. Southwest Jiaotong University, 2017.

5. X.H Wu, Y.D Wang. The characteristics of Mandala in monastic architecture of Tibetan Buddhism [J]Shanxi Architecture, 2006, (23):39-41.

6. H. Zong, H. Cui, Y. Fu. Characteristic Research on Plant Landscape of Temple Garden in Eastern Sichuan Province [J]. Journal of Human Settlements in West China, 2015, 30(06):107-112.

7. H. Gao. Cases Study on Wetland Park the Landscape Art Form: Chengdu Huoshui Park and Xixi National Wetland Park [D]. Chongqing University, 2009.

8. J. Tang, Y.Y. Luo. The research of wild plant introduction and ecological landscape diversity in Chengdu living water park [J]. Journal of Sichuan University (Natural Science Edition), 2010,47(01):167-174.

9. Y.K. He. Study on the Plants Landscape of Urban Wetland - the Case of Chengdu [D]. Southwest Jiaotong University, 2013. 